ANUARIO DE Estudios MEDIEVALES

46/1, enero-junio de 2016, pp. 137-165

ISSN 0066-5061

doi:10.3989/aem.2016.46.1.04

\title{
TRES VIOLANTES: LAS MUJERES DE UNA FAMILIA EN EL PODER A LO LARGO DEL SIGLO XIII ${ }^{1}$
}

\author{
THREE VIOLANTES: WOMEN OF A FAMILY \\ IN POWER DURING THE XIII CENTURY
}

\author{
MARÍA JeSÚs Fuente PÉREZ \\ Universidad Carlos III de Madrid
}

\begin{abstract}
Resumen: El interés por el tema del poder de las mujeres, en particular de las reinas, ha planteado muchos interrogantes sobre la naturaleza de ese poder. "Tres Violantes" examina la participación de dos reinas y una infanta de una misma familia, en aspectos diversos de la vida de las coronas de Aragón y Castilla en el siglo XIII, con el objetivo de apreciar si el papel de las reinas hispanas, en particular su participación política, siguió un camino similar al de las reinas de ese tiempo que, como bien se ha estudiado para las inglesas, fueron perdiendo autoridad y se vieron limitadas a ejercer poder a través de la intercesión y mediación.
\end{abstract}

Palabras clave: Violante de Hungría; Violante de Aragón; Violante de Castilla; poder femenino; intercesión; mediación.

\begin{abstract}
The power of women, in particular the power of queens, has been a topic of great interest to historians, medievalists in particular; though much has been written about the subject, many questions remain. "Three Violantes" will look at the role of two Iberian queens and one Spanish princess in the thirteenth century Iberian kingdoms. In England and in other European kingdoms of that time, queens had lost authority and their agency was limited to the power of intercession and mediation, I will try to determine whether this also holds true for the Iberian queens.
\end{abstract}

Keywords: Violante de Hungría; Violante de Aragón; Violante de Castilla; power of women; intercession; mediation.

\section{SUMARIO}

Introducción.- 1. La reina, una pieza valiosa por herencia.- 2. La reina, pieza rica y dadivosa.- 3. La reina, pieza valiosa por sí misma.- 4. Conclusión: ¿sin fuerza, ni poder ni autoridad?.- 5. Bibliografía citada.

${ }^{1}$ Abreviaturas: $\mathrm{ACA}=$ Archivo de la Corona de Aragón; $\mathrm{AHN}=$ Archivo Histórico Nacional; $\mathrm{C}=$ Cancillería; caj. $=$ caja; cap. = capítulo; carp. = carpeta; doc. $=$ documento; perg. = pergaminos; reg. $=$ registro. 


\section{INTRODUCCIÓN}

Y tú, que eres una simple mujer, que no tienes fuerza, ni poder ni autoridad más que el que se te ha dado por otros... ¿piensas que puedes supeditar y superar el mundo a tu voluntad? ${ }^{2}$

Cristina de Pizan planteaba este interrogante en El libro de las tres virtudes, y apuntaba la fórmula para contrarrestar la falta de fuerza, poder y autoridad de las mujeres: utilizar el talento para persuadir. Solo con astucia e inteligencia una mujer podía imponer su voluntad, aunque hubiera de recurrir a otros para conseguirlo. Una reina jugaba con la ventaja de poder interceder ante quien tenía la máxima capacidad de concesión, su esposo el rey. Cristina de Pizan recurría a un ejemplo muy didáctico: si el monarca, mal aconsejado por algunos, hubiera impuesto un tributo muy pesado a sus súbditos, éstos, que sienten a su señora llena de bondad, de piedad y de caridad, irán a ella y muy humildemente la suplicarán que interceda por ellos ante el rey3.

La autora francesa, como otros escritores medievales, utilizó a la reina bíblica Esther para dar cuerpo a un modelo femenino con las cualidades necesarias para permitir a las mujeres triunfar en la corte ${ }^{4}$. Cristina de Pizan se inspiró en fuentes bíblicas y religiosas, en particular en el Antiguo Testamento, donde pudo encontrar ejemplos de mujeres que habían actuado con astuta inteligencia en situaciones delicadas o difíciles ${ }^{5}$. Utilizando la intercesión o la mediación, las mujeres en general y las reinas en particular podían influir en la política de la casa o del reino.

¿Fueron esas también las formas de participación política de las reinas de los reinos hispánicos?, ¿por qué, cuándo y cómo intervenían?, ¿conseguían los objetivos que se planteaban?, ¿fueron ellas quienes eligieron esos métodos o se vieron abocadas a aceptarlos? Para responder a estas preguntas voy a enfocar a unas mujeres de la misma familia que ocuparon posiciones de poder en los reinos hispánicos durante el siglo XIII: Violante de Hungría, reina de Aragón (1236-1251); su hija Violante de Aragón, reina de Castilla (12521284), y su nieta la infanta Violante de Castilla, noble señora feudal (finales del siglo XIII). Enfocar a estas mujeres es de especial interés porque vivieron el tiempo de maduración política que afecta a la cristiandad occidental a lo

${ }^{2}$ Pizan 2003, p. 12.

${ }^{3}$ Ibidem.

${ }^{4}$ Adams 2011, p. 121.

${ }^{5}$ Frymer-Kensky 1992, p. 129. 
largo del siglo XIII ${ }^{6}$, cuando comenzaban a definirse los papeles a asignar al rey y a la reina. ¿Fue entonces cuando se consideró la intercesión o la mediación como tarea política propia de las reinas?

Los estudiosos de las reinas medievales inglesas han apuntado una evolución del papel de las reinas, que muestra pérdida de autoridad, ejercida por algunas por derecho propio, y salvaguardia de poder mediante el recurso a la intercesión o la mediación, tareas específicas admitidas para la realeza femenina ${ }^{7}$. Defienden estos autores que, desde mediados del siglo XII, la introducción de burocracias profesionales y los cambios en la forma de heredar erosionaron el derecho de las mujeres a reclamar la herencia del trono. La reina fue perdiendo autoridad, entendida como el derecho públicamente reconocido a dar órdenes y esperar que se cumplan, y su tarea política quedó limitada a funciones que le conferían poder, entendido como habilidad de hacer que la gente haga cosas utilizando métodos que implican presión, influencia, persuasión y coerción ${ }^{8}$.

En el proceso de construcción o definición de la monarquía a partir del siglo XII, se constata que el rey procuraba acumular poderes, mientras se producía el proceso inverso en la reina; los reyes iban subiendo peldaños en su escalada hacia el autoritarismo, y las reinas se estancaban, si no iban descendiendo, al delimitarse su tarea política y quedar constreñida a la intercesión y mediación. Estas dos formas de intervención política suelen entenderse como una misma cosa, se funden o se confunden, sin embargo, hay matices diferenciadores en ambos cometidos. Interceder es hablar en favor de alguien para conseguirle un bien o librarlo de un mal (Diccionario de la Real Academia Española), o intervenir con una persona para que no castigue o trate mal a otra o para que acceda a algo pedido por ésta (Diccionario de uso del español de María Moliner); mediar tiene otro matiz: interponerse entre dos o más que riñen o contienden, procurando reconciliarlos y unirlos en amistad (Diccionario de la Real Academia Española), sentido complementado en el Diccionario de uso del español de María Moliner que define mediar como intervenir en el arreglo de un trato o de una diferencia o riña entre otros. $\mathrm{Al}$ margen de matices, ambos cometidos conferían poder a las mujeres. Siguiendo una de las acepciones del término poder (ser contingente o posible que suceda algo), las reinas, como otras mujeres, podían hacer que algo sucedie$\mathrm{ra}$, sin olvidar que era contingente de la voluntad de los maridos aceptar la

\footnotetext{
${ }^{6}$ Ayala 1986, p. 146.

${ }^{7}$ Entre los historiadores que han estudiado este fenómeno se encuentran Huneycutt 1993; Parsons 1995; Stafford 1997; Howell 1998.

${ }^{8}$ Los conceptos de poder y autoridad han sido, y son, muy debatidos. Me inclino por seguir la clara explicación de St. John 2012, p. 9.
} 
petición, algo que estaba lejos de conferirles autoridad como poder que gobierna o ejerce el mando, de hecho o de derecho (Diccionario de la Real Academia Española), o poder reconocido y legitimado 9 .

El estudio de las Violantes tratará de comprobar si ese proceso identificado en la monarquía inglesa, se desarrolló en las reinas de los reinos hispánicos. Para ello hay que observarlas en foros diversos, en particular en la vida familiar y política, contemplar sus intervenciones y valorar su influencia, aportaciones y logros que dependerían de factores muy diversos: sus cualidades, sus necesidades, o sus posibilidades de actuación. Estudiando juntas a tres generaciones de mujeres de una misma familia se persigue iluminar también aspectos tan diversos como el interés político de sus matrimonios, sus relaciones con la familia y el reino o señorío de origen y de acogida, así como sus semejanzas y diferencias con otras reinas del entorno europeo.

Para realizar este estudio comenzaré por los aspectos familiares (interés de la alianza matrimonial para los reinos de origen y de llegada, dote y arras, y aportación de elementos culturales, políticos o de otra índole del reino de procedencia), para seguir por la intervención en asuntos diversos (patrocinio cultural, religioso o laico), en particular de carácter político (participación en la escena política, razones para ello y consecución de expectativas que se esperaban de su matrimonio), y concluir con una reflexión sobre la práctica política de estas reinas y su posible inclusión en los modelos teóricos que se han venido aplicando a la participación política de las mujeres de la realeza medieval. Tendrá limitaciones por la parquedad de las fuentes ${ }^{10}$, pero también por el requisito de extensión de los estudios de esta revista.

Hace años recurría a la pieza de la reina en el juego de ajedrez como metáfora del papel de las reinas en la Edad Media ${ }^{11}$. Sin embargo, la libertad de movimientos en todas direcciones que tiene esa pieza del ajedrez, bien diferente a lo permitido a cualquier otra pieza, no era símbolo de la libertad de la reina medieval. Parecería, pues, apropiado revisar esa metáfora, sin embargo, aunque la reina medieval no tenía tan gran libertad de movimientos, era muy importante conquistar su favor, ganarse a la reina, pues ella podía ser insupe-

\footnotetext{
${ }^{9}$ Bardsley 2007, p. 193. Esta autora sigue los conceptos de poder y autoridad defendidos por Bennett 1988,pp. 24 y ss.

${ }^{10}$ Documentos tan importantes como la dote y arras no se han conservado siempre, y en el caso concreto de estas tres mujeres, solo han subsistido los documentos de Violante de Hungría. De las crónicas de los reyes, me he limitado a utilizar el Libro de los Hechos para el monarca aragonés, y la Crónica de Alfonso X para el monarca castellano. Aunque estas fuentes puedan contener errores, no siempre desinteresados, me he cuidado de utilizar de ellas solo los datos que se constatan por otras fuentes documentales. Por otra parte, a falta de mejor documentación hay que atender a las informaciones que tenemos.

${ }^{11}$ Fuente 2003, pp. 12-13.
} 
rable intercesora ante el rey por compartir con él la familiaridad, que, junto al patronazgo y a las alianzas negociadas, era uno de los elementos esenciales del ejercicio del poder real ${ }^{12}$. En este sentido es buena metáfora, pues en ajedrez se gana la partida al conseguir la pieza de la reina.

\section{LA REINA, UNA PIEZA VALIOSA POR HERENCIA}

Las tres Violantes fueron excelentes piezas en el tablero político del siglo XIII. La intencionalidad política de sus matrimonios responde a una táctica bien cuidada de alianzas e intereses políticos de los reinos que unían a su progenie en matrimonio. Las tres eran hijas de rey, dos se casaron con reyes, y la tercera, también prometida a un rey, hubo de unirse a alguien de inferior rango, aunque miembro de una influyente familia de la alta nobleza castellana.

Como es bien sabido, las princesas tenían un valor que iba más allá de sus propios méritos personales. Su valor dependía en buena medida de la cuna en la que habían nacido, y se plasmaba de forma palpable en las cantidades que se negociaban a la hora de su matrimonio, y menos palpable en las influencias, culturales o de otra índole, que pudieran aportar. Esto, que es general a las princesas europeas de aquel tiempo, se ha de contemplar para estimar la importancia de las tres Violantes como "piezas valiosas".

El interés de celebrar el enlace de Violante de Hungría con Jaime I de Aragón se vislumbra en las negociaciones y embajadas que intercambiaron ambos reinos ${ }^{13}$. Hija de Andrés II Arpad de Hungría, Violante fue hija de otra Violante, Violante de Courtenay, hija del emperador del Imperio Latino de Constantinopla, Pedro II, y de su esposa, Violante de Flandes. La negociación de una boda de este calibre se hizo muy meticulosamente. Los embajadores húngaros fueron el obispo de Pecs (Cincoiglesias) Ber$\operatorname{talan}^{14}$, y otro noble llamado Beraldo. Los negociadores efectuaron cuatro viajes al reino de Aragón, a Barcelona probablemente, en los años 1229$1230^{15}, 1233,1234-1235$ y 1235 . Presentaron una oferta de dote que luego fue ligeramente modificada por algunas circunstancias. Jaime I aceptó, tal como consta en el documento final de la dote, en el que figuran los nuncios

\footnotetext{
${ }^{12}$ Gilsdorf 2014, p. 6.

${ }^{13}$ La producción bibliográfica a raíz del centenario de Jaime I es ingente, pero no se ha citado a todos los autores a no ser que aporten datos verdaderamente relevantes para este artículo.

${ }^{14}$ Koszta 1996, pp. 78 y ss.

${ }^{15}$ Estas fechas tan tempranas las aporta ibidem, p. 86.
} 
designados por el rey de Aragón, Assellico de Gudal y Peregrino de Bolas ${ }^{16}$, dos nobles relevantes del reino ${ }^{17}$.

Si las negociaciones del matrimonio de Violante de Hungría han permanecido bastante bien documentadas, no se puede decir lo mismo de las otras dos Violantes ${ }^{18}$. Ello no significa falta de interés hacia ellas por parte de los "reinos contrayentes", de hecho el matrimonio de la hija del rey de Aragón con el heredero del trono de Castilla, era de un alto interés político. Tomó la iniciativa Jaime I que envió al obispo de Huesca, Vidal de Cañellas, a hablar con Fernando III y su hijo Alfonso. Dada la rivalidad entre Aragón y Castilla, esa unión buscaba una armonía muy necesaria. Tras la concertación del matrimonio probablemente en $1240^{19}$, su celebración tuvo lugar en 1249.

Si son escasísimas las noticias de esa negociación, más lo son aún las referentes a la boda de la infanta Violante de Castilla, aunque su enlace con Diego López de Haro tenía también un alto interés político. Para esta Violante había habido otros planes, se había concertado su matrimonio con el hijo de Enrique I de Navarra, el infante Teobaldo, como parte de la alianza que buscaba Alfonso X con el reino navarro en momentos de dificultad con los nobles castellanos. La muerte accidental de Teobaldo hizo cambiar los planes, se le buscó un nuevo marido, y en 1282 se casó con Diego López de Haro. Esta unión formaba parte del sistema de alianzas matrimoniales con el que su hermano, el futuro rey Sancho IV, quería fundamentar la adhesión del estamento nobiliario a su causa. Los Haro, tradicionalmente vinculados al reino de Castilla ${ }^{20}$, habían abandonado la fidelidad al rey castellano y se habían pasado al bando aragonés desde comienzos del reinado de Alfonso $\mathrm{X}^{21}$. Con este enlace, Sancho pretendía la adhesión de un miembro de una importante casa nobiliaria, y la vuelta al redil castellano de la familia de los Haro $^{22}$.

Sin un interés político tan preciso como los de su hija y su nieta, es el matrimonio de Violante de Hungría el que mejor se conoce. Aunque posiblemente las negociaciones hubieran comenzado antes de 1233, fue ese año

${ }^{16}$ ACA, C, Perg., Jaime I, Serie general, 0635. Con esta grafía aparecen los nombres de los negociadores en este documento latino de la dote que el rey Arpad promete entregar a su hija.

${ }^{17}$ En varios documentos de Jaime I escritos en latín se encuentra a Pelegrinus de Bolas o Peregrinus de Bolas como maiordomus curie, Cabanes 2009, documentos 24, 30 y 34, pp. 50-51, 57-58, 62-63. Es posible que no fuera mayordomo, sino que actuara en nombre de D. Ato de Foces, Caruana 1956, p. 376.

${ }^{18} \mathrm{La}$ "escasa huella en la documentación y en los testimonios de los contemporáneos" es señalada por Francisco de Moxó en su estudio de las negociaciones del enlace de Alfonso de Castilla con Violante de Aragón, Moxó 1989, p. 69.

${ }^{19}$ Oliver-Brachfeld 1942, p. 83; Moxó 1989, p. 84.

${ }^{20}$ Prieto Lasa 2013.

${ }^{21}$ Ayala 2004-2005, p. 107.

${ }^{22}$ El Papa Martín IV se opuso a esta boda, Domínguez Sánchez 2010, p. 156. 
cuando el obispo Bertalan se desplazó a Barcelona para presentar una oferta de dote: 10.000 marcos de plata, procedentes de la dote de Yolanda de Courtenay, madre de la joven a desposar, la concesión del derecho de recobro de 200 marcos de oro que el duque de Austria debía al rey Andrés II de Hungría, y otros bienes procedentes de la herencia que había de recibir de su madre, las propiedades de Yolanda de Courtenay en Flandes (Namur), Francia (Borgoña) y Hungría (el condado de Pozsony, actual Bratislava), así como el mobiliario. Esta dote fue modificada, de manera que en el documento final aparecen suprimidos los 200 marcos de oro por 2.000 marcos de plata, siendo finalmente 12.000 marcos de plata el dinero efectivo de la dote. En la dote venían incluidas también las deudas que había dejado su madre, y que Violante probablemente tampoco pagó, como figura en su testamento ${ }^{23}$.

Las arras que Jaime I entregó a Violante fueron en primer lugar la ciudad de Montpellier con todas sus pertenencias y el condado de Amillau ${ }^{24}$, y días después le asignó el condado de Cerdaña, Conflent, Vallespir, y el castillo y la villa de Colliure ${ }^{25}$. Diez años después del enlace, en 1246, Jaime entregó a Violante una segunda tanda de territorios, casi coincidentes con los que en 1221 había entregado como dote a Leonor de Castilla: Daroca, Epila, Uncasti1lo, Barbastro, Tamarite, San Esteban, Montalbán, Cervera, y Prades ${ }^{26}$ (varios en una amplia franja lindante entre Aragón y Castilla).

Como se ha apuntado antes, no se han conservado documentos de la dote y arras de Violante de Aragón, no porque se hayan perdido, sino porque quizás no existieron. El Libro de los Hechos cuenta que Alfonso X reclamó a Jaime I la localidad de Xàtiva cuando se reunieron en Almizra en 1244, con el argumento de que había recibido la promesa del rey aragonés de que recibiría esa plaza como parte de la dote de Violante. Tras consultar con su esposa, el rey Jaime respondió que nunca había ofrecido ese lugar a nadie, que cuando él se casó con Leonor no le dieron dote alguna, y que por ello ahora pensaba hacer lo mismo ${ }^{27}$. Aunque Violante de Hungría parece coincidir con el rey en la negativa a entregar dote a su hija, ella en su testamento menciona las joyas que había entregado a Violante de Aragón cuando contrajo matrimonio ${ }^{28}$. No hay tampoco documento de arras, o no se ha conservado, sin embargo, una carta de Fernando III a Jaime I hace una mención a las arras que han de entregar

${ }^{23}$ ACA, C, Perg., Jaime I, Serie general, 1264.

${ }^{24}$ ACA, C, Perg., Jaime I, Serie general, 0659.

${ }^{25}$ ACA, C, Perg., Jaime I, Serie general, 0661.

${ }^{26}$ ACA, C, Perg., Jaime I, Serie general, 1024.

${ }^{27}$ Butiña 2003, cap. 345.

${ }^{28}$ ACA, C, Perg., Jaime I, Serie general, 1264. 
a la princesa, aunque no menciona qué ${ }^{29}$. Enrique Flórez apunta que esas arras fueron muy copiosas y señala entre otros lugares las ciudades de Valladolid, Palencia, San Esteban de Gormaz, Astudillo, Ayllón, Curiel y Béjar ${ }^{30}$. No todas estas localidades fueron parte de las arras de Violante de Aragón, en particular no lo fue la ciudad de Palencia, señorío del obispo de la ciudad. Probablemente Flórez lo confundió con Plasencia, que sí perteneció a la reina. El resto de lugares citados posiblemente fueran parte de las arras recibidas por Violante de Aragón, y a ellos habría que añadir Hervás, Plasencia, Hontoria (cerca de Tariego) y Olmillos.

Este último lugar de Olmillos de Sasamón pasó luego a formar parte de la dote de Violante de Castilla, tal como apunta El Libro de las Behetrías: lo dio en donadio la reyna doña Violante a don Diego (López de Haro) en casamiento con su fija ${ }^{31}$. También se sabe que el lugar de Villatuelda lo entregó Sancho IV, y Violante de Aragón, a Violante de Castilla, su hermana e hija respectivamente. A falta de un documento de dote y arras, no sería arriesgado suponer que recibiría mucho más que esos dos lugares citados. Cualquier comparación con mujeres poderosas de ese tiempo llevaría a justificar esa afirmación.

Si se conocen bastante bien los movimientos de concertación de estos enlaces, las bodas están ausentes de la documentación conservada. La ceremonia "mejor conocida", por lo muy discutida, es la de Alfonso X de Castilla y Violante de Aragón. Llama la atención por las ausencias más que por las presencias; no asistieron los reyes, ni acudieron miembros de las casas nobiliarias más importantes, sino solamente personas del entorno más cercano de los contrayentes, como el ama de Alfonso o el ayo de Violante. Entre las escasas noticias sobre la concertación de este matrimonio, hay alguna referencia a que se esperaba que los padres de los contrayentes acudieran a Uclés, lugar que en principio se consideraba el más apropiado para la boda, pero en Valladolid, donde finalmente se ofició el enlace, no apareció ninguno de ellos. Parece que hubo mucha prisa por celebrarlo, y no se pudo, o no se quiso, esperar a organizar una ceremonia más opulenta ${ }^{32}$.

Las dos reinas que se asentaron en Aragón y en Castilla, en la década de 1230 la primera y en la de 1240 la segunda, llegaron por razones similares, pero lo hicieron de forma muy distinta. Violante de Hungría tenía cerca de veinte años cuando viajó a Barcelona, mientras que su hija fue llevada

\footnotetext{
${ }^{29}$ Valls-Taberner 1919, p. 17.

${ }^{30}$ Flórez 2002, p. 512. Flórez no indica de dónde saca la información, que, por otra parte, ha servido para confundir a muchos que le han seguido.

${ }^{31}$ Becerro 1865, p. 171.

${ }^{32}$ Moxó 1989, p. 87.
} 
a Burgos con menos de diez. Los viajes fueron muy distintos. El viaje desde Hungría fue muy largo, los kilómetros que tuvo que hacer la comitiva de Esztergom a Barcelona fueron cerca de 2.000. Viajaron en verano, y Violante llegó en setiembre a Barcelona. No se conoce bien el itinerario, excepto su paso por Perpignan donde el tío del rey, Nuño Sánchez, organizó brillantes fiestas en su honor ${ }^{33}$. El viaje no duraría menos de dos meses. Acompañaron a Violante un grande de Hungría, el conde Dionis, y una comitiva numerosa de tropas de escolta, criadas, cocineras, cazadores, tesoreros y orfebres, palafreneros $^{34}$. Como personas más cercanas a la princesa vinieron su amiga Doña Jordana, a quien el rey casó con Bernardo de Peñafort, su nodriza, su capellán, el monje cisterciense Nicolás, su médico, D. Guido, y los pajes Gregorio y Archimbaldo ${ }^{35}$.

La edad de la princesa al llegar al reino en el que iba a pasar el resto de su vida, es un aspecto importante a tener en cuenta a la hora de considerar la influencia cultural, política o de otra índole que la reina extranjera podía traer al reino. La reina de Aragón, que había vivido dos décadas en Hungría, ¿aportaría formas culturales y políticas de su tierra de origen? Las maneras políticas de las mujeres de la familia Arpad, como las de otros reinos europeos, no tenían "protocolos" establecidos, de manera que la influencia de algunas reinas de los siglos XII y XIII se debió a razones de índole circunstancial y no a una norma ${ }^{36}$. La primera esposa de Andres II, Gertrudis de Andechs-Meran intervino en la política del reino más allá de lo deseado por los nobles, que, resentidos con la actuación de la reina cuando fue regente en ausencia de su esposo y por los favores del rey a la familia de su esposa, se rebelaron y la asesinaron. Gertrudis fue la madre de Santa Isabel de Hungría, y hermana de Santa Eduvigis de Andechs. Tras su asesinato, Andrés II se casó con Violante de Courtenay y tuvieron una hija, Violante de Hungría. De la actividad de Violante de Courtenay solo se podría decir que contribuyó a la paz al no generar conflictos ni padecerlos. Parece que no le causó problemas la designación de su padre como emperador del Imperio Latino de Constantinopla, cuando a ese puesto aspiraba su esposo. Violante de Courtenay fue la única esposa de Andrés II que no se enfrentó a los nobles o familiares del rey, al contrario, procuró mantener buenas relaciones con los hijos que su esposo tuvo con Gertrudis de Andechs-Meran. La tercera esposa de Andrés II, Beatriz de Este, fue acusada de adulterio cuando declaró, a la muerte del rey, que estaba embarazada. Huyó del país con la ayuda del emperador Federico II.

${ }^{33}$ Oliver-Brachfeld 1942, p. 51.

${ }^{34}$ Vajay 2009,p. 245.

${ }^{35}$ Oliver-Brachfeld 1942, p. 55.

${ }^{36}$ Bak 1993,p. 19. 
Con el precedente de su madre, difícilmente podría esperarse de Violante de Hungría una continuidad de la obra política de sus parientas las reinas húngaras. Sin embargo, se ha afirmado que como reina de Aragón, Violante va cercar en la seva memòria familiar les maneres polítiques de l'àvia paterna Margarida ${ }^{37}$. Su abuela paterna era Margarita de Francia, hija de Luis VII de Francia y Constanza de Castilla, que se casó con Bela III de Hungría, con quien tuvo a Andres II. Antes de casarse con el rey húngaro, Margarita de Francia había sido esposa de Enrique Plantagenet, hijo de Enrique II de Inglaterra y Leonor de Aquitania. Algunas mujeres de la familia habían sido, pues, figuras destacadas en el mundo político del último tercio del siglo XII y del primer tercio del XIII. Aunque probablemente menos por tradición que por convicción, la participación política de Violante de Hungría es digna de resaltar, y más adelante me ocuparé de ella.

Otra cosa es la posible contribución de Violante a los aspectos culturales del reino de Aragón. Teniendo en cuenta que una boda real es una forma de transmisión de cultura, hay que rastrear las posibles repercusiones culturales del enlace de la princesa de Hungría con el rey de Aragón. La primera secuela es el propio nombre de la reina, que desde ese momento se incorporó al repertorio de nombres de mujer en los reinos peninsulares. Pero Violante introdujo algo más que un nombre; entre otras cosas significativas y duraderas se encuentra la entrada del culto a Santa Isabel, su media hermana, canonizada el mismo año de la llegada de Violante al reino de Aragón ${ }^{38}$. También influyó en la dedicación de iglesias a San Andrés, haciendo honor, y como recuerdo, al nombre de su padre. Si a esto se limitó la influencia cultural de Violante de Hungría en el reino de Aragón, no podría afirmarse que su impacto fuera grande, aunque sería posiblemente el más duradero.

Sin embargo, en la proyección cultural habría que añadir el posible influjo de los personajes de su séquito que se instalaron de manera definitiva en el reino de Aragón. Quienes llegaron con la princesa y se instalaron en Cataluña, en Aragón o en Valencia, traían porciones de su forma de vida, de su moral, y de otros aspectos de su cultura entre los que se encontraba su propia lengua. El impacto cultural húngaro ¿fue duradero?, ¿cuánto tardaron los descendientes del séquito de la princesa en adoptar las formas culturales aragonesas? Son preguntas de difícil respuesta, aunque no sería arriesgado suponer que fue el séquito más que la princesa quien pudo dejar secuelas de manera más duradera, y que esas secuelas fueron esfumándose con cierta rapidez. En cualquier caso, habría que considerar la afirmación de Szabolcs

\footnotetext{
${ }^{37}$ Ruiz-Domènec 2009, p. 212.

${ }^{38}$ Klanicza 2002, p. 421. Afirma que la fecha de canonización por Gregorio IX fue el 1 de junio de 1235 .
} 
de Vajay, que apunta la importancia de estos desplazamientos de princesas de unas partes a otras de Europa, pues, el grupo de élite que las acompañaba, ejercía una fecunda influencia sobre el reino de llegada, con lo que podían contribuir a la formación de una cultura europea común ${ }^{39}$. El problema radica en la dificultad de conocer, o medir con rigor, cómo se plasma esa influencia, en otras palabras, en qué consiste, cómo se manifiesta y cuánto dura, algo que no puede verificarse más allá de los puntos arriba indicados.

Por otra parte, hay que pensar que la reina habría de adaptarse a las costumbres y cultura de la corte a la que se incorporaba. Una incógnita es cómo se adaptó a la lengua de su esposo, pues su lengua madre era el húngaro. Oliver Brachfeld señala que, por su familia materna, ella hablaría la lengua d'oil, mientras él hablaría en lengua d'oc, lo que le lleva a limitarse a afirmar simplemente que se entenderían "en romance" 40.

Si Violante de Hungría pudo aportar elementos culturales de su tierra de origen, sería difícil esperar que su hija Violante de Aragón introdujera elementos culturales aragoneses en Castilla. Aunque hay gran imprecisión sobre la fecha de la firma de esponsales, la princesa Violante era muy joven cuando la llevaron de Aragón a Castilla. Vivió tan poco tiempo en Aragón, que no podría adquirir o arraigar una cultura aragonesa-catalana que transmitir a Castilla. La finalidad de llevar a las princesas al reino de su futuro marido para conseguir una más fácil integración pudo cumplirse bien en el caso de Violante de Aragón, que desde muy niña vivió educada en la corte castellana. Llegó con ella a Castilla el hombre que había sido su educador en el reino de Aragón, Jofré de Loaysa, que, junto a su esposa Jacometa, continuó la formación de la princesa. Si Violante aportó algunos aspectos a la cultura de los reinos de Castilla y León, sería difícil identificarlos como rasgos culturales aragoneses-catalanes.

Si la integración de las reinas en la familia a la que llegaban hacía difícil el mantenimiento de la impronta cultural del reino del que salían, no pasaba lo mismo con los lazos emocionales, que solían mantener y que las hacían sentirse parte de una familia que, a pesar del poco contacto, las apoyaba en caso de necesidad. En efecto, la familia de procedencia les daba apoyo como les había proporcionado prestigio, y aunque la familia no tuviera contactos frecuentes, los valores familiares estaban presentes en algunos de los aspectos de la vida personal o política. Si el afecto parecía estar ausente, regresaba en momentos necesarios, tal como puede verse en los comportamientos de Violante de Aragón, que, cuando necesitaba apoyo, se

\footnotetext{
${ }^{39}$ Vajay 2009, p. 257.

${ }^{40}$ Oliver-Brachfeld 1942, p. 62.
} 
dirigió a su padre para conmover sus sentimientos. De los sentimientos hacia el padre o entre los hermanos hay algunas referencias en el Libro de los Hechos. Ante el temor de una importante pérdida territorial de Alfonso X, Violante de Aragón escribió a su padre, que decidió ayudarla porque no puedo fallar a mi hija ni a mis nietos, ahora que se les quiere desheredar ${ }^{41}$. Las malas relaciones con su yerno no mermaban sus deseos de comportarse como se esperaba de un buen padre y abuelo, aunque su hija no había vuelto a poner el pie en los reinos de su padre. Violante volvió cuando Jaime I accedió a reunirse con Alfonso X en el camino entre Requena y Buñol, y el rey aragonés le invitó a entrar en Valencia, convencido además de que su hija Violante se alegraría de acompañarle, tal como apunta en el Libro de los Hechos: agradando mucho a la reina, ya que desde que la habíamos casado con el rey de Castilla no había vuelto a nuestra tierra ${ }^{42}$. Violante volvió en otras ocasiones ${ }^{43}$.

Así pues, las conexiones y afectos familiares no se perdían con la distancia. Las referencias a la familia interesaban especialmente cuando algunos de sus miembros habían sido elevados a la santidad, como santa Isabel de Hungría y santa Margarita de Hungría, la primera hermanastra de Violante de Hungría, y la segunda sobrina, pues era hija de Bela IV, hermanastro de la reina aragonesa. La conexión con mujeres santas elevaba a la familia en general y a la reina en particular; no es de extrañar, pues, que en la Crónica de los Reyes de Castilla, Jofré de Loaysa señalara que la reina Violante de Hungría era sororis beate Helisabet ${ }^{44}$.

\section{LA REINA, PIEZA RICA Y DADIVOSA}

En el año 1248 se firmó un arbitraje entre el Infante Pedro de Portugal y Jaime I el Conquistador:

dirigido por la esposa de Jaume, la reina Violant d'Hongria juntamente con un comité de hombres eminentes, y relativo a "la expulsión de los sarracenos" del gran feudo valenciano de Almenara-Castellón-Sagunto-Segorbe, propiedad de Pedro de Portugal ${ }^{45}$.

${ }^{41}$ Butiña 2003, cap. 382, p. 419.

${ }^{42}$ Ibidem, cap. 501, p. 503.

${ }^{43}$ Pero-Sanz 2011, p. 19.

${ }^{44}$ Loaysa 1961, p. 64.

${ }^{45}$ Burns 1987, p. 254. 
Este documento plantea varias cuestiones: ¿por qué Jaime I encargó esta misión a su esposa Violante?, ¿qué funciones desarrollaba esta reina para que su esposo le confiara esa tarea?, ¿cuál era la relación política de la reina con el rey y el reino? La respuesta a estas preguntas se encuadra en el amplio marco de las prerrogativas de la reina y de la definición de su poder o autoridad a lo largo de los siglos medievales, y permite contemplar el panorama de un tiempo tan crucial como el siglo XIII en relación con el rumbo que tomó el poder o autoridad de las reinas, asunto que plantea nuevas preguntas, entre otras si creció, disminuyó o se re-direccionó su poder e influencia.

Utilizando los ejemplos de Violante de Hungría y su hija Violante de Aragón trataré fundamentalmente dos aspectos: las actividades de patrocinio de las reinas, y su participación en la vida política del reino.

Antes de abordar sus actividades en la escena cultural, económicosocial y política de su tiempo, hay que apuntar los medios económicos de que disponían, para valorar sus posibilidades de patrocinio cultural o religioso, o de hacer concesiones de favor a personas de su entorno. Ninguna de las dos Violantes comenzó su reinado siendo rica. La familia de la princesa húngara no estaba en condiciones de favorecerla económicamente, pues ya cuando se negoció la dote la situación económica del rey de Hungría no era precisamente boyante; los 12.000 marcos de plata de la dote negociada, nunca llegaron a manos de Violante ${ }^{46}$. Tampoco contribuyó el rey de Aragón al patrimonio de su hija Violante de Aragón; su riqueza cuando llegó a Castilla se reducía a las joyas donadas por su madre. Ambas, pues, eran piezas valiosas por el prestigio familiar, pero sin valor económico inicial. La riqueza de ambas se forjó en el reino en que reinaron.

Violante de Hungría fue reuniendo propiedades, donaciones de su esposo, y con ellas pudo contribuir a causas de diversa índole, en particular al patrocinio de instituciones religiosas. Eligió para su descanso eterno el monasterio de Vallbona de las Monjas, centro al que había favorecido en vida. Inició el patrocinio a las órdenes mendicantes que se extendían con fuerza en su tiempo, y dio ejemplo a sus ocho hijos, que continuaron el apoyo a esas órdenes ${ }^{47}$. Aparte de las mandas que se anotan en su testamento, cooperó a la fundación de algunos conventos. En 1241 el papa Gregorio IX le envió la bula Gratum gerimus, dándole las gracias en nombre de las religiosas del convento de Santa Isabel de Lérida por haber comprado el solar donde se erigió el convento, alabando su acción y exhortándola a continuar favoreciéndolas ${ }^{48}$.

${ }^{46}$ Miquel 1948,p. 87.

${ }^{47}$ Jaspert 2009, p. 297.

${ }^{48}$ Miquel 1948, p. 69. 
Violante participó como ejecutora testamentaria del caballero Luis de Cervelló, con cuyo motivo donó a la catedral de Barcelona muchas y preciosas joyas $^{49}$. La generosidad de la reina llegó a quienes la acompañaron a Aragón desde Hungría. De ellos no se olvidó en su testamento, encomendándolos al rey ${ }^{50}$.

Su hija Violante de Aragón también consiguió reunir un buen patrimonio. Aparte de las arras citadas antes, recibió donadíos en las repoblaciones de Sevilla y Murcia, y fue señora de las localidades murcianas de Alguazas $^{51}$ y Alcantarilla ${ }^{52}$. Violante participó, junto con su esposo, en los canjes entre el rey y la orden de Calatrava, tal como muestran los documentos de donación o canje entre ambos monarcas y esa orden militar ${ }^{53}$. Con el importante patrimonio que había conseguido reunir, Violante ayudó a instituciones religiosas, y a sus servidores más próximos; el lugar de Benicotó ${ }^{54}$, parte del repartimiento de Murcia, recayó en algunos de los servidores de la casa de la reina: su repostero y mensajero, su copero, su acemilero, sus porteros, su doncella y sus criadas. Siguiendo con la tradición de apoyo a las órdenes mendicantes, Violante, junto a su esposo, participó en la fundación de algunas comunidades de clarisas. Como patrocinio de Violante en solitario hay que citar las ayudas a los dominicos ${ }^{55}$ y franciscanos de Valladolid, y a otras instituciones del clero de esa ciudad, entre ellas el Cabildo de Santa María la Real, al que confirmó las donaciones que habían recibido del conde de Urgel ${ }^{56}$. También se la considera fundadora de las claras de Allariz (Orense), monasterio al que concedió sustanciosos privilegios y algunos regalos (una virgen abrideira ${ }^{57}$, y una cruz de $\operatorname{altar}^{58}$ ). En realidad la fundación de Allariz, en 1286, fue una concesión de su hijo Sancho IV, pues para entonces Violante tenía poco patrimonio, ya que su marido y su hijo Sancho la despojaron de prácticamente todas sus propiedades.

De quien se conoce mucho menos es de su hija Violante de Castilla, aunque hay que pensar que no dejaría de tener las actividades de patrocinio propias de las mujeres de la realeza y la alta nobleza, tal como muestran los

\footnotetext{
${ }^{49}$ Oliver-Brachfeld 1942, p. 57. Señala que el documento se encuentra en la catedral de Barcelona.

${ }^{50}$ ACA, C, Perg., Jaime I, Serie general, 1264.

${ }^{51}$ Torres Fontes 1977, pp. 86 y ss.; Pujante 1997, p. 477. El señorío aparece documentado en el año 1295, aunque se desconoce desde cuando la reina era señora de ese lugar.

${ }^{52}$ Frutos 1973; Pujante 1997, p. 477.

${ }^{53}$ AHN, Documentos Calatrava, caj. 70, n. 19. Cit. Vargas-Zúñiga, Cuartero 1949, p. 283.

${ }_{54}$ Torres Fontes 1963.

${ }_{55}$ Mañueco, Zurita 1917-1920, tomo I, p. 293.

${ }^{56}$ Ibidem, tomo I, pp. 178-179.

${ }^{57}$ Katz 2009, 2011.

${ }^{58}$ La referencia a esta cruz se encuentra en Fitz-James Stuart 1931, p. 169.
} 
pocos documentos que de ella han quedado. Pudo reunir una buena fortuna, procedente de su dote y arras, y de algunas otras donaciones que probablemente recibió. Aparece entre los receptores de donadíos del repartimiento de Murcia junto a sus hermanos, que hacen concesiones de heredades a los más allegados de sus servidores: la infanta doña Violante a su amo Velasco Pérez ${ }^{59}$. Juntamente con su esposo Diego López de Haro, XV señor de Vizcaya, hizo donación en 1287 a favor de Sancha Díaz de Haro, hermana de Diego López, de la aldea de Santa Olalla (Toledo) ${ }^{60}$. Años después, en 1291, se la encuentra actuando sola en un documento de salvaguarda al abad y convento del monasterio de Piedra:

por muchos servicios que nos an fecho e nos fasen de que somos en esta tierra de Aragón Tomamos los en nuestra guarda e en nuestra comienda e en nuestro defendimiento a ellos e a sos vasallos e a sos ganados e a todas las otras sos cosas por do quier que las ayan ${ }^{61}$.

Señala que conoce que su esposo Don Diego, si en ese momento hubiera estado en Calatayud, donde residían, hubiera redactado un documento igual. Violante de Castilla actuaba en solitario, pero sabiendo que su esposo suscribiría su acción.

\section{LA REINA, PIEZA VALIOSA POR SÍ MISMA}

La reina se puso a llorar diciendo que en mala hora había nacido, pues ella había venido para conciliarnos con su yerno y ahora veía que acababa tan mal. El Libro de los Hechos cuenta así la tristeza de Violante de Hungría tras reunirse con su futuro yerno, el infante Alfonso, para tratar de resolver el problema de Játiva, y no conseguirlo.

Ella de que vio al rey su padre dexose caer della bestia en que venía, dando muy grandes vozes. Et el rey quando la vio, entendió que era la reyna su fija et fue muy marabillado ${ }^{62}$. El Libro de las Armas de Don Juan Manuel narra así la escena en la que Violante de Aragón se presenta ante su padre Jaime I para rogarle que impida el matrimonio de su hermana Constanza con el infante Enrique de Castilla, ante el temor de que eso pudiera resultar en merma de los derechos sucesorios de sus hijos.

${ }_{59}$ Torres Fontes 1960, p. 221.

${ }^{60}$ AHN, Sección Nobleza, Osuna, carp. 3912, doc. 59.

${ }^{61}$ AHN, Clero secular-regular, carp. 3682, doc. 8.

${ }^{62}$ Manuel 1982,pp. 129-130. 
Ambos ejemplos son buenas muestras de la intervención política de las Violantes mediante las fórmulas consideradas propias de las reinas: mediación e intercesión. El primero es un ejemplo de mediación: Violante de Hungría trataba de lograr la conciliación entre dos partes, su esposo y su futuro yerno. El segundo es un ejemplo de intercesión: Violante de Aragón solicitaba a su padre, el rey Jaime, beneficios para sus hijos.

Los matices diferenciadores de estas intervenciones conducen al tema de los límites entre el poder y la autoridad de las reinas. La intercesión era, sin duda, un ejercicio de poder, pero, ¿lo era también la mediación, o podría verse en ella un ejercicio de autoridad? Ayudará a responder esta pregunta examinar algunas acciones de intercesión y mediación de estas reinas, y exponer las circunstancias y las razones que las dejaron intervenir, entre las que no puede faltar la estima que de ellas tenían sus propios esposos.

Antes de entrar en este examen hay que apuntar la intención de los reyes de utilizarlas desde el momento de contraer matrimonio, o incluso antes. Cuando Jaime I se casó con Violante de Hungría, el rey comenzaba la campaña de conquista de Valencia. Violante le siguió a esa misión e intervino en decisiones y acciones políticas requeridas en aquellas circunstancias. Pero ya antes de la llegada de Violante a Barcelona, es decir, antes del matrimonio, Jaime I tenía intenciones de utilizarla, o, al menos eso podría deducirse de las palabras del rey en el Libro de los Hechos: cuando nos hayamos apoderado de Burriana, mandaremos venir a la reina, nuestra mujer, para que la gente comprenda que tenemos la intención de quedarnos ${ }^{63}$. Teniendo en cuenta que esta redacción es posterior a los hechos, habría que cuestionar si esas ideas eran realmente las que el rey tenía en mente cuando se produjeron los acontecimientos ${ }^{64}$. En cualquier caso, la intención de asentar allí a la reina denota que la presencia de ésta daba fuerza a la política del rey.

En el tiempo del asalto final a Valencia, Violante hizo el camino para reunirse con su esposo acompañada de Don Fernando, tío del rey.Los tres se reunieron en Peñíscola, donde conferenciaron, y Don Fernando recomendó a su sobrino que antes de comenzar el asedio a Valencia considerara que una hazaña de tal calibre no se podría efectuar sin entrar en nuestros reinos, sin poder hablar con nuestros hombres ni ellos con $N_{0 s}{ }^{65}$. De ese mismo parecer era Violante que se adhirió a lo que él había dicho, puesto que los dos se habían puesto de acuerdo por el camino ${ }^{66}$. El rey no siguió el consejo de su tío, y éste se volvió, quedándose Violante con su esposo para iniciar el viaje a Burriana.

${ }^{63}$ Butiñá 2003, cap. 130, p. 212.

${ }^{64}$ Kagay 1996.

${ }^{65}$ Butiñá 2003, cap. 240, p. 314.

${ }^{66}$ Ibidem. 
La presencia de la reina en Burriana intimidó a Zaén, el rey de Valencia, que, como supo que habíamos hecho venir a nuestra mujer, le entró un gran mied $o^{67}$. Zaén envió un emisario a Jaime I con una magnífica oferta de lugares, pero no sirvió para tentar al rey de Aragón, convencido de que era el momento de hacerse con Valencia. Mientras el rey se movía y actuaba desde el Puig, la reina residió en Burriana hasta que su esposo se hizo con el castillo de Almenara y la mandó llamar para que se instalara en ese lugar.

En el momento crucial del asedio a Valencia, Violante tuvo un papel notable, como la más leal copartícipe del rey. Ante la noticia que le llevó un enviado de Zaén, Alí Albacá, el rey decidió visitar a la reina para comunicarle la propuesta, y aceptarla siempre que a ella le pareciera bien, y que le rogábamos y ordenábamos que nadie de la hueste lo supiese, sino Nos, ella y el mensajero ${ }^{68}$.

Jaime I destacaba el papel de Violante como única persona merecedora de toda su confianza. Sabía que ella deseaba lo mejor para él, mientras que muchos de los nobles que le acompañaban aspiraban a conseguir de la campaña beneficios para ellos en particular. Por ello fue a Violante a quien hizo partícipe del secreto.

Un segundo emisario, el arráez Abulhamalec, se reunió con el rey, y éste le indicó que quería que estuviera presente la reina. El emisario respondió que lo agradecía porque delante de la reina nos esmeraríamos por nuestra imagen y de ello se beneficiaría el pacto ${ }^{69}$. La presencia de la reina daba fuerza y solidez a los proyectos de Jaime I.

En la negociación del pacto final con el poder árabe vuelve a aparecer Violante, la única persona a quien el rey de nuevo consulta:

Ella nos dijo que, si a Nos nos parecía un pacto digno de aceptarse, ella lo daba por bueno, pues, aun pudiendo tener Valencia de un día para otro, no debía arriesgarse.

Nos juzgamos que nos aconsejaba bien y le dijimos que aceptábamos el consejo ${ }^{70}$

Prudencia de la reina, e ímpetu del rey. Decisión conjunta aparentemente, aunque a la hora de comunicar lo decidido al arráez Abulhamalec, el rey lo hizo en primera persona, sin mencionar a la reina.

Si el rey valoró mucho la inteligencia política de su esposa, los nobles del reino seguramente también valoraban esa cualidad de la reina, de ahí

${ }^{67}$ Ibidem, cap. 242, p. 316.

${ }^{68}$ Ibidem, cap. 271, p. 336.

${ }^{69}$ Ibidem, cap. 276, p. 341.

${ }^{70}$ Ibidem, cap. 278, p. 342. 
que en algunos momentos la reclamaron como intercesora. En el episodio narrado arriba en el que la reina llora su supuesto fracaso como mediadora entre Jaime y Alfonso, aparecen también los nobles del reino que les acompañaban, que entendían que era el orgullo del rey el que provocaba situaciones de esa índole, y por ello se dirigían a la reina para pedir su intervención ${ }^{71}$.

La reina se había ganado muy pronto la confianza de los nobles. Inició su intervención en la política poco después de su llegada a Barcelona en 1235, y durante la década de 1240 participó activamente en aspectos políticos diversos. En 1248 intervino en el arbitraje entre el infante Pedro de Portugal y Jaime I, enfrentados por la orden del rey de echar a los árabes de los lugares de los que el infante era señor, tal como consta en el documento apuntado antes. Violante halló medios de compensar a Pedro de Portugal, y presentó una fórmula de consenso que pudiera complacer a ambos y que además pudiera mantenerse largamente. El rey la puso al cargo de este asunto, y de otros que requerían inteligencia para la mediación.

Como ella, su hija Violante de Aragón participó activamente en la vida política de la corona de Castilla, como intercesora y como mediadora. Su actividad intercesora comenzó pocos años después del ascenso al trono de su esposo Alfonso X. En 1256, una revuelta nobiliaria contra el rey contó con el apoyo del infante Enrique, hermano de Alfonso X. El infante pidió ayuda al rey de Aragón y pretendió casarse con una de sus hijas, la infanta Constanza, hermana de Violante. Ésta, tan pronto conoció esos planes, pidió una entrevista con su padre, y se presentó en el lugar convenido, Calatayud, con dos de sus hijos. Como se ha apuntado antes, Violante rogó a su padre que no concediera apoyo al infante Enrique y no consintiera su matrimonio con Constanza. El mensaje de Violante surtió efecto, pues aunque Jaime I no era proclive a romper el acuerdo con el infante Enrique, tras el pacto que sellaron Alfonso X con Jaime I en Soria, complació a su hija ${ }^{72}$.

Violante volvió a interceder ante su padre. Fue en 1264, cuando la revuelta de los mudéjares del reino de Murcia y de la parte de Andalucía conquistada por Castilla representaba una amenaza de primer orden para Alfonso X. Violante acudió a su padre, cuyo socorro era fundamental para controlar la revuelta y recuperar el poder en esos territorios. Jaime I, a pesar de las reticencias de parte de la nobleza de sus reinos, decidió intervenir para complacer la petición de su hija, aunque probablemente lo hizo también por el interés estratégico y político de no dejar ese territorio en manos de los árabes. El rey tenía razones políticas para ayudar al rey de Castilla, pero resaltaba el motivo

${ }^{71}$ Ibidem, cap. 348, p. 392.

${ }^{72}$ Ballesteros 1984, pp. 129-130. 
familiar con estas palabras apuntadas también antes: no puedo fallar a mi hija ni a mis nietos, ahora que se les quiere desheredar ${ }^{73}$.

Jaime I no consideró preciso pedir consejo para tomar la decisión, reunió las cortes para pedir apoyo a la resolución que él ya había tomado. Las dificultades que le pusieron sus súbditos no le frenaron. La intercesión de Violante ante su padre había tenido éxito. La reina también ejerció la intercesión ante su hermano el rey Pedro III de Aragón. Entre varios ejemplos se puede apuntar cómo, en 1274, Pedro III hizo donación a Guillermo Ayvar de la cuarta de pan y vino de Ateca, a petición de su hermana la reina de Castilla ${ }^{74}$.

No faltó la intercesión ante su esposo, algo que apunta el ordenamiento que hizo Alfonso X en las cortes de Sevilla de 1264, dirigido a la Extremadura $^{75}$. El rey afirmaba que los concejos extremeños enviaron a sus representantes para solicitar la intermediación de la reina ante el rey, del que querían conseguir una menor carga impositiva. Esos representantes consiguieron abrir una vía de comunicación directa ${ }^{76}$ entre caballeros y rey, con el compromiso de que si el rey no pudiera atenderlos, sería la reina quien lo hiciera ${ }^{77}$. Una carta enviada por Alfonso X desde Sevilla a Madrid tiene un mensaje similar, y responde a la petición del concejo de Madrid a la reina Violante ${ }^{78}$.

Para el año 1264 en que Violante recibió las súplicas de los extremeños, la reina ya había comenzado su actividad política en otros asuntos. En 1263 medió entre la ciudad de Valladolid y los Frailes Menores y Dominicos que no se entendían, aunque su éxito no duró mucho y hubo de repetir el arbitraje en años posteriores (1267 y 1276) (79 $^{79}$ En 1264 intervino en la controversia entre el concejo y el obispo de la ciudad de León, enviando una carta a Fernán Fernández, alcalde del rey, en esa ciudad ${ }^{80}$.

Los asuntos en los que la reina intervino fueron delicados y trascendentes, en concreto dos conflictos graves del reinado de Alfonso X: las revueltas de los mudéjares y de los nobles. En la primera utilizó la intercesión ante su padre, como se ha apuntado antes, y en la segunda tuvo una intervención directa, que merece especial atención.

En 1269, cuando Jaime I fue a Burgos para asistir a la boda de su nieto Fernando, conoció el descontento nobiliario contra su yerno Alfonso X.

${ }^{73}$ Butiñá 2003, cap. 382, p. 419.

${ }^{74}$ ACA, C, Reg., número 37, f. 71r.

${ }^{75}$ González Jiménez 2004, p. 159.

${ }^{76}$ Asenjo 1997, p. 114.

${ }^{77}$ Iglesia 1983, p. 520.

${ }^{78}$ Ibidem, p. 480.

${ }^{79}$ Mañueco, Zurita 1917-1920, tomo II, p. 93.

${ }^{80}$ Ruiz Asencio 1994, p. 423. 
Se entrevistó con Nuño González de Lara, cabeza de la rebelión, quien le informó de las quejas de los nobles contra el rey. Aunque Alfonso no lo ignoraba, no hizo frente a la revuelta nobiliaria hasta 1272 , cuando vio que los rebeldes habían llegado incluso a tratar de convencer al príncipe heredero, Fernando de la Cerda, de que se rebelase contra su padre. Ante esa situación Alfonso reunió a su consejo, a aquellos de quienes podía fiarse, entre ellos la reina Violante, los obispos de Cádiz y Córdoba, y don Jofré de Loaysa. Decidieron avenirse con los rebeldes y complacerles en la medida de lo posible, algo que fue más negativo que positivo. Ese año se afrontó el problema en las Cortes de Burgos, donde, acosado por los nobles, el rey nombró una comisión, presidida por la reina y su hermano Sancho, arzobispo de Toledo, para debatir los problemas y emitir recomendaciones.

Ante lo que podía considerarse un triunfo del rey en las Cortes de Burgos, los nobles rebeldes decidieron "desnaturalizarse", y solicitaron abandonar el reino. La reina y su hermano el arzobispo de Toledo apremiaron a Alfonso para hacer más concesiones a los nobles: confirmar sus fueros y acceder a sus peticiones, pero los nobles no aceptaron, y se prestaron a un pacto de alianza y sumisión al rey de Granada. Para dialogar con los rebeldes, Alfonso tuvo por bien de enviar la Reina doña Violante, su mujer, a Córdoba, para que ella e el infante don Fernando librasen el fecho de los ricos omes e que los trajesen a servicio del Rey ${ }^{81}$. Reunidas las partes en Sabiote (Jaén), los delegados de Alfonso presentaron a los nobles un escrito que decía: Estas son las cosas que la reina e el arzobispo... pidieron al rey, por merced, que otorgase al infante Don Felipe e a los ricos omes, sobre las demandas que le ficieron ${ }^{82}$, lo que, a pesar de la buena voluntad de doña Violante, no beneficiaba al rey, pues parecía recompensar la rebeldía ${ }^{83}$.

Violante arbitró la revuelta nobiliaria, llevando adelante las conversaciones. Fue a Andalucía a negociar con los rebeldes, y asistió a los "ayuntamientos" de Almagro y Ávila, reunidos para resolver el asunto. En Ávila el rey la encargó la misión de apaciguar a los rebeldes, indicándole los puntos en los que era preciso incidir, pero no el modo de hacerlo, al contrario, mandóla e rogóla que lo librase lo más a su honra que pudiese... otrosí, porque libró ella mejor de commo gelo mandó el rey ${ }^{84}$.

Violante tuvo que seguir llevando las riendas del problema hasta buscar una solución, que llegó en 1273, tras reunirse con el rey de Granada y los rebeldes, encabezados por Nuño González de Lara. Ambas negociacio-

${ }^{81}$ Crónica de Alfonso X, cap. LIII, p. 152.

${ }^{82}$ Ibidem, cap. XL, p. 114.

${ }^{83}$ Ballesteros 1984, p. 618.

${ }^{84}$ Crónica de Alfonso X, cap. LIII, p. 152. 
nes fueron fructíferas. Del rey de Granada, Muhammad II, consiguió 300.000 maravedíes a pagar anualmente a la corte alfonsí. En el acuerdo iba implícito que los arráeces rebeldes al rey granadino volverían a su obediencia, como los nobles castellanos volvieron a la obediencia del rey Alfonso, sin embargo, Violante probablemente ni siquiera intentó el asunto de los arráeces. La reina tuvo que urdir una historia ante Muhammad excusándose por no haber comunicado a su esposo la entrevista mantenida con el rey de Granada, y pidiendo a este una tregua para negociar ese punto tan fundamental para el rey granadino ${ }^{85}$.

El otro gran asunto en que intervino Violante, aunque de forma ambigua, fue el de la sucesión del reino. Al morir en 1275 el infante Fernando, la reina tomó partido por sus nietos, los infantes de la Cerda, y ante las desavenencias con su esposo, huyó a Aragón con su nuera y sus nietos ${ }^{86}$, aunque luego volvió a Castilla, y pasó a apoyar a su hijo Sancho.

Los problemas del reinado de Alfonso X, como los de otros monarcas, llegaban a involucrar a toda la familia real, a unos de forma activa y a otros de forma pasiva. En la revuelta de los nobles, la reina Violante de Aragón tuvo un papel muy activo. A su hija Violante de Castilla le alcanzó también el problema, aunque de forma pasiva. Los nobles buscaron el apoyo del rey de Navarra, que no mostró interés en la alianza ${ }^{87}$. El rey de Castilla aprovechó el momento para proponer un pacto a Navarra, y antes de presentarse en las Cortes de Burgos de 1272, negoció un compromiso de ayuda mutua con el reino navarro. Ese acuerdo se selló con el matrimonio de Violante de Castilla con Teobaldo de Navarra ${ }^{88}$. Violante contribuía así a la causa de su padre. La muerte de Teobaldo dejó a Violante de Castilla relegada a un papel menos destacado.

De manera directa o indirecta, participando en asuntos políticos del reino, las Violantes defendieron la política de la casa, es decir, los intereses de la red que la familia había ido tejiendo, y en la que no solía haber resquicios, de forma que se apoyaban mutuamente cuando alguien de la familia tenía necesidad de ayuda. En esa línea ambas reinas se batieron por los miembros de la familia que más les importaban, sus hijos.

A Violante de Hungría se le ha hecho responsable de los problemas de división que padeció el reino durante los años de su reinado. Como madre protectora pretendió que Jaime I concediera dominios a sus hijos en los territorios recién conquistados, teniendo como tenían el escollo del hijo primogénito de Jaime, el infante Alfonso, heredero de los reinos. Violante de Hungría

${ }^{85}$ Martínez 2003, p. 378.

${ }^{86}$ Valdeón 2003, p. 212.

${ }^{87}$ Martínez 2003, p. 341.

${ }^{88}$ O'Callaghan 1996, p. 264. 
trabajó intensamente para conseguir que sus hijos tuvieran una herencia regia. Lo mismo hizo Violante de Aragón, que intervino siempre que veía tambalearse los derechos hereditarios de sus hijos.

Por unas razones u otras, en particular por necesidades en circunstancias concretas, estas reinas intervinieron activamente en la escena política y desempeñaron papeles importantes, manteniendo las formas políticas usuales en las reinas: intercesión, consejo y mediación. No se trata de tareas que manifiesten un poder limitado de las reinas. No es difícil vislumbrar la autoridad de la reina en las negociaciones que Violante de Hungría realizó con el príncipe Pedro de Portugal, ni la autoridad de Violante de Aragón en sus conversaciones con los nobles castellanos rebeldes o con el rey de Granada.

La participación política de Violante de Hungría fue más allá de la forma discreta de acción política ${ }^{89}$ que es la intercesión. Su papel de consejera del rey muestra una acción política con autoridad, especialmente si se tiene en cuenta el valor del consilium en la gobernanza real. Jaime I subraya, en el Libro de los Hechos, la intercesión de la reina, lo que apunta a una forma de participación política bien valorada en aquel tiempo, una porción de poder reconocida que atañía a la reina, a la de Hungría en particular, pero probablemente también a otras reinas. Lo mismo habría que decir de la acción política de Violante de Aragón, con su intervención en asuntos en los que podía ejercer autoridad.

Las aptitudes políticas de ambas reinas quedaban bien de manifiesto, y sus esposos valoraban su actuación, no solo porque en ellas encontraban consejeras en quien confiar, sino porque veían en ellas cualidades para la intervención en asuntos no siempre fáciles ${ }^{90}$.

Las cualidades intercesoras y mediadoras de Violante de Aragón fueron valoradas por otras instancias. Habiendo quedado de manifiesto la confianza que inspiraba a los concejos arriba citados, habría que añadir al Papa, que la suponía buena negociadora cuando le escribió una carta solicitándola que interviniera para convencer a Alfonso X de que abandonara la idea del "fecho del Imperio" 91.

\section{CONCLUSIÓN: ¿SIN FUERZA, NI PODER NI AUTORIDAD?}

No dejaba de tener razón Cristina de Pizan cuando preguntaba en El libro de las tres virtudes si una mujer podía con su mandato supeditar y

\footnotetext{
${ }^{89}$ Gilsdorf 2014, p. 153.

${ }^{90}$ Alfonso X en una carta agradecía a su esposa que " $\tan$ bien e tan a su servicio librara estos fechos", Crónica de Alfonso X, cap. LV, p. 158.

${ }^{91}$ Guiraud 1892, p. 299.
} 
superar el mundo ${ }^{92}$, y también tenía razón cuando señalaba que las mujeres solo podían tener el poder y autoridad que otros les conferían o confiaban, sin embargo, esta afirmación precisa de ciertos matices. La participación política de las Violantes demanda una aclaración de esa idea de Cristina de Pizan, y la revisión de algunas ideas acerca del papel de las reinas en la política de los reinos. Voy a enfocar dos líneas de pensamiento: en primer lugar la que considera que las reinas fueron perdiendo autoridad para quedarse con el poder que les confería su tarea esencial, la intercesión, y en segundo lugar la línea que define la realeza femenina (queenship) como asociación o colaboración (partnership) con el rey su esposo.

El examen de la actividad política de las dos Violantes pone de manifiesto que ambas desarrollaron tareas políticas que demostraban poder y autoridad. Si en otras reinas o en otros reinos europeos se ha constatado la pérdida de autoridad de las reinas, y la limitación de su tarea a la intercesión, esto no solo no se puede probar en ambas Violantes, sino que su actuación señala justamente lo contrario. En algunos aspectos la tarea de las reinas hispanas fue afín a la de las reinas de otros espacios de Europa occidental, algunas de ellas emparentadas con las reinas hispanas; Violante de Aragón y su cuñada Leonor de Castilla, reina de Inglaterra (1272-1290), son un buen ejemplo. Ambas fueron alabadas como buenas intercesoras por el Papa, el clero, la nobleza y el pueblo, aparte de por su propio marido ${ }^{93}$. Pero la reina de Castilla no se limitó a ser intercesora, su labor mediadora en la resolución de conflictos del reino, teniendo en cuenta que la mediación puede considerarse la operación política por excelencia ${ }^{94}$, lleva a afirmar su autoridad. Siguió los pasos de su madre, Violante de Hungría, y fue seguida por su hija, Violante de Castilla, que muestra autoridad en el documento citado de salvaguarda al abad y convento del monasterio de Piedra.

Las tres Violantes actuaron en algunos momentos de su vida con una autoridad fuera de toda duda. ¿Era, como afirmaba Cristina de Pizan, una autoridad que otros les conferían? No hay evidencias que permitan suscribir esta afirmación. No sería arriesgado suponer que la tarea de Violante de Hungría, máxima confidente de su esposo, no era una concesión de Jaime I, ni que la mediación de Violante de Aragón en asuntos importantes del reino de Castilla era simple delegación del rey. Ejercían autoridad y poder por ellas mismas, se introducían en los círculos de poder como hijas y esposas de reyes importantes. La marca de la herencia no significó poder ni autoridad en otras reinas

${ }^{92}$ Pizan 2003, p. 12.

${ }^{93}$ Cockerill 2014; Parsons 1995.

${ }^{94}$ Muraro 2000, p. 12. 
o nobles mujeres medievales, solo se convertía en poder y autoridad si se les sumaban unas cualidades personales, o unas circunstancias particulares que les exigieran o permitieran intervenir.

No se encuentra ejercicio de autoridad en otras mujeres con las que Jaime I o Alfonso X se relacionaron. No lo ejercieron ninguna de sus otras dos esposas, ni Leonor de Castilla, que fue llamada reina toda su vida aunque su matrimonio fuera anulado, ni Teresa Gil de Vidaurre, que ni siquiera recibió título de reina.

Las fórmulas utilizadas para ejercer poder y autoridad variaban dependiendo de las circunstancias. El recurso a la intercesión era el más fácil y factible por ser la reina quien tenía familiaritas y acceso al rey como nadie en el entorno del monarca, y era de la familiaridad de lo que dependía la intercesión ${ }^{95}$. La mediación era otro asunto, la reina podía ejercerla para ayudar a su esposo en momentos necesarios, pero no tenía que acudir al rey para conseguir lo que pretendía. Era una forma de intervención política al mismo nivel que la participación del rey, bien lo hiciera la reina por iniciativa propia o en colaboración con su esposo. En este último caso, la reina estaría haciendo un ejercicio de asociación, en línea con lo que se ha llegado a definir como realeza femenina ${ }^{96}$.

Parece evidente que la participación política de algunas reinas se limitó a ser colaboradoras de sus esposos, pero eso solo no puede definir a la realeza femenina (queenship). De hecho si ese fuera el rasgo definidor de la realeza femenina, no sería muy distinta la definición de realeza masculina (kingship) especialmente en los casos en que rey y reina actuaron conjuntamente, en asociación o colaboración (partnership), bien de manera permanente o bien en casos esporádicos. La participación política en asociación conjunta, rasgo de la realeza femenina y de la masculina, parece la fórmula común, o al menos frecuente, de ejercicio del poder de rey y reina, tal como puede deducirse de los documentos reales que apuntan la actuación de la reina a una con el rey.

La casuística es tan amplia y diversa, que no parece posible hablar de arquetipos. Sería arriesgado definir un arquetipo de reina hispánica, ni siquiera un arquetipo circunscrito a las reinas del siglo XIII, Violante de Hungría y Violante de Aragón, siendo como eran madre e hija, y no habiendo una distancia temporal considerable entre una y otra. Ambas comparten algunos rasgos, pero difieren en otros, si bien hay trazos que podrían compartir con reinas de otros tiempos y espacios.

${ }^{95}$ Gilsdorf 2014, p. 117.

${ }^{96}$ Earenfight 2008, p. 16. 
Las Violantes actuaron al margen de lo que se había buscado al casarlas. En el caso de Violante de Hungría no se puede ver más allá de la constatación de la apertura diplomática entre Occidente y Oriente, pues una vez instalada en Aragón su preocupación prioritaria fue la política de este reino y la concesión de territorios a sus hijos. En el caso de Violante de Aragón no se cumplió el objetivo de lograr paz entre Aragón y Castilla; una vez instalada en Castilla tuvo como objetivo prioritario el bien del reino de Castilla y la defensa de los intereses de sus hijos y nietos.

¿Se podría pensar en el inicio de un modelo o arquetipo a partir de Violante de Aragón? No sería arriesgado suponer que Alfonso X tuviera presente a su esposa cuando mandó redactar las Partidas, pues aunque no apuntaba expresamente las funciones consideradas propias de una reina, al referir los méritos a tener en cuenta para elegir compañera, dejaba entrever lo que se esperaba de su acción y participación.

La ausencia de unas características específicas, que pudieran aplicarse a las dos Violantes estudiadas, y a otras reinas hispanas predecesoras y sucesoras de ellas, y el hecho de que su actuación coincida con la de algunas reinas europeas de su tiempo, hace difícil demostrar la existencia de una realeza femenina "ibérica", como difícil podría ser también buscar un arquetipo de realeza femenina "europea", pues las reinas actuaban de acuerdo con unas circunstancias, y se movían fuera de arquetipos rígidos, lo que llevaría a recordar, aunque lejanamente, la libertad de la reina en el juego de ajedrez.

\section{BIBLIOGRAFÍA}

Adams, Tracy (2011), Appearing Virtuous: Christine de Pizan's Le Livre des trois vertus and Anne de France's Les Enseignements d'Anne de France, pp. 115-132, en Green, Karen; Mews, Constant J. (eds.), Virtue Ethics for Women 1250-1500, Nueva York, Springer Verlag.

Asenjo González, María (1997), Ciudades y hermandades en la Corona de Castilla. Aproximación sociopolítica, "Anuario de Estudios Medievales" 27/1, pp. 103-146.

Ayala, Carlos de (1986), Directrices fundamentales de la política peninsular de Alfonso X: relaciones castellano-aragonesas de 1253 a 1263, Madrid, Antiqua et Mediaevalia.

Ayala, Carlos de (2004-2005), Relaciones de Alfonso X con Aragón y Navarra, "Alcanate" 4, pp. 101-146.

Bak, János M. (1993), Roles and Functions of Queens in Árpádian and Angevin Hungary (1000-1386 A.D.), en Parsons, John Carmi (ed.), Medieval Queenship, Nueva York, Saint Martin's Press, pp. 13-24.

Ballesteros Beretta, Antonio (1984), Alfonso X, Barcelona, El Albir. 
Bardsley, Sandy (2007), Women's Roles in the Middle Ages, Westport - Londres, Greenwood Press.

Becerro: libro famoso de las behetrías de Castilla (1865), Santander, Imprenta de la Gaceta del Comercio.

Bennett, Judith M. (1988), Public Power and Authority in the Medieval English Countryside, en Erler, Mary C.; Kowaleski, Maryanne (eds.), Women and Power in the Middle Ages, Athens, University of Georgia Press, pp. 18-36.

Burns, Robert I. (1987), La guerra de Al-Azraq de 1249, "Sharq Al-Andalus: estudios mudéjares y moriscos" 4, pp. 253-256.

Butiñá Jiménez, Julia (ed.) (2003), Jaime I. Libro de los Hechos, Madrid, Gredos.

Cabanes Pecourt, María de los Desamparados (2009), Documentos de Jaime I relacionados con Aragón, Zaragoza, Institución Fernando el Católico, CSIC.

Caruana, Jaime (1956), Los mayordomos de Aragón en los siglos XII y XIII, "Revista de Archivos, Bibliotecas y Museos" 62/2, pp. 349-377.

Castro, Manuel de (1983), El real monasterio de Santa Clara, de Santiago de Compostela, "Archivo Ibero-Américano" 43, pp. 3-61.

Cockerill, Sara (2014), Eleanor of Castile: The Shadow Queen, Stroud, Amberley.

Crónica de Alfonso X, ed. Manuel González Jiménez (1999), Murcia, Real Academia Alfonso X el Sabio.

Domínguez Sánchez, Santiago (2010), Documentos de Martín IV (1281-1285) referentes a España, León, Universidad de León.

Earenfight, Theresa (2008), Two bodies, one spirit: Isabel and Fernando's Construction of Monarchical Partnership, en Weisberger, Barbara (ed.), Queen Isabel I of Castile. Power, Patronage, Persona, Woodbridge, Boydell \& Brewer, pp. 3-18.

Fitz-James Stuart y Falcó, Jacobo (1931), Catálogo histórico y bibliográfico de la Exposición Internacional de Barcelona de 1929, t. I., Madrid, Real Academia de la Historia.

Flórez, Enrique (2002), Memorias de las Reynas Catholicas, edic. facsímil, 2 vols., Valladolid, Junta de Castilla y León.

Frutos Hidalgo, Salvador (1973), El señorío de Alcantarilla, Alcantarilla, Ayuntamiento de Alcantarilla.

Frymer-Kensky, Tikva (1992), In the Wake of the Goddesses: Women, Culture, and the Biblical Transformation of Pagan Myth, Nueva York, Macmillan - Free Press.

Fuente Pérez, María Jesús (2003), Reinas Medievales en los Reinos Hispánicos, Madrid, La Esfera de los Libros. 
Galera Gracia, Antonio (2007), La verdadera historia de la orden del templo de Jerusalén: a la luz de la documentación histórica, Madrid, Edaf.

Gilsdorf, Sean J. (2014), The Favor of Friends. Intercession and Aristocratic Politics in Carolingian and Ottonian Europe, Leiden, Brill.

González Jiménez, Manuel (1996-1997), La sucesión al trono de Castilla: 1275-1304, "Anales de la Universidad de Alicante. Historia Medieval" 11 , pp. 201-212.

González Jiménez, Manuel (2004), Alfonso X el Sabio, Barcelona, Ariel.

Guiraud, Jean (1892), Les registres de Grégoire X (1272-1276), recueil de bulles de ce Pape, París, Thorin et fils.

Hernández, Francisco J. (2015), La reina Violante de Aragón, Jofré de Loaysa y la Crónica de Alfonso X. Un gran fragmento cronístico del siglo XIII reutilizado en el XIV, "Journal of Medieval Iberian Studies" 7/1, pp. 87-111.

Howell, Margaret (1998), Eleanor of Provence. Queenship in Thirteenth-Century England, Oxford, Blackwell.

Huici Miranda, Ambrosio; Cabanes Pecourt; María Desamparados (19781988), Documentos de Jaime I de Aragón, 5 vols., Valencia, Anubar.

Huneycutt, Lois L. (1993), Female Succession and the Language of Power in the Writings of Twelfth-Century Churchmen, en Parsons, John Carmi (ed.), Medieval Queenship, Nueva York, Saint Martin's Press, pp. 189-201.

Iglesia Ferreirós, Aquilino (1983), El privilegio general concedido a las Extremaduras en 1264 por Alfonso X. Edición del ejemplar enviado a Peñafiel el 15 de Abril de 1264, "Anuario de Historia del Derecho Español" 53, pp. 455-521.

Índice de los documentos de la orden militar de Calatrava existentes en el Archivo Histórico Nacional (1899), Madrid, Establecimiento Tipográfico de Fortanet.

Jaspert, Nikolas (2009), Els descendents piadosos d'una princesa hongaresa. Heretgia $i$ santedat al casal de Barcelona durant els segles XIII $i$ $X I V$, en Princeses de terres llunyanes: Catalunya i Hongria a l'edat mitjana, Barcelona, Generalitat de Catalunya, pp. 291-305.

Kagay, Donald J. (1996), The Line Between History and Memoir: Jaime I and the Llibre dels Feyts, "Mediterranean History Review" 11, pp. 165-176.

Katz, Melissa (2009), Behind Closed Doors: Distributed Bodies, Hidden Interiors, and Corporeal Erasure in Vierge ouvrante Sculpture, "Journal of Anthropology and Aesthetics" 55/56, pp. 194-221.

Katz, Melissa (2011), Marian Motion: Opening the Body of the Vierge ouvrante, en Zchomelidse, Nino; Freni, Giovanni (eds.) Meaning in Motion: 
Semantics of Movement in Medieval Art and Architecture, Princeton, Princeton University Press, pp. 63-91.

Klanicza, Gábor (2002), Holy Rulers and Blessed Princesses: Dynastic Cults in Medieval Central Europe, Cambridge, Cambridge University Press.

Komlódi, Zsuzsanna (1997), Doña Violante de Hungría, en Actas XXXII Congreso internacional de la Asociación Europea de Profesores de Español. Español: uniendo culturas, Valencia, Asociación Europea de Profesores de Español, pp. 129-135.

Koszta, László (1996), Un prélat français de Hongrie: Bertalan, évêque de Pécs (1219-1251), "Cahiers d'études hongroises" 8, pp. 71-96.

Loaysa, Jofre de (1961), Crónica de los reyes de Castilla Fernando III, Alfonso X, Sancho IV y Fernando IV (1248-1305), Murcia, Diputación.

Mañueco Villalobos, Manuel; Zurita Nieto, José (eds.) (1917-1920), Documentos de la Iglesia Colegial de Santa María la Mayor (hoy metropolitana) de Valladolid, Valladolid, Sociedad de Estudios Históricos Castellanos.

Manuel, Don Juan (1982), Libro de las armas. Obras completas, ed. José Manuel Blecua, vol. I., Madrid, Gredos.

Martínez, H. Salvador (2003), Alfonso X, el Sabio. Una biografía, Madrid, Polifemo.

Miquel Rosell, Francisco J. (1948), Regesta de letras pontificias del Archivo de la Corona de Aragón, Madrid, s.n.

Moxó y Montoliu, Francisco de (1989), El enlace de Alfonso de Castilla con Violante de Aragón: marco político y precisiones cronológicas, "Hispania" 49, pp. 69-110.

Muraro, Luisa (2000), Autoridad y autoría, en Segura Graíño, Cristina; Cerrada Jiménez, Ana Isabel (coords.), Las mujeres y el poder. Representaciones y prácticas de vida, Madrid, Al-Mudayna, pp. 9-22.

O’Callaghan, Joseph (1996), El Rey Sabio. El reinado de Alfonso X, Sevilla, Universidad de Sevilla.

Oliver-Brachfeld, Ferenc (1942), Doña Violante de Hungría, Reina de Aragón, Barcelona, La Gacela.

Parsons, John C. (1995), The Queen's Intercession in the Thirteenth Century England, en Carpenter, Jennifer; MacLean, Sally-Beth (eds.), The power of the weak, Chicago, University of Illinois Press, pp. 147177.

Parsons, John Carmi (1995), Eleanor of Castile. Queen and Society in Thirteenth-Century England, Nueva York, St. Martin's Press.

Pero-Sanz, José Miguel (2011), Santa Isabel: reina de Portugal, Madrid, Palabra. 
Pizan, Cristina de (2003), The Treasure of the City of Ladies or the Book of the Three Virtues, ed. Sarah Lawson, Londres, Penguin Books.

Prieto Lasa, J. Ramón (2013), La genealogía de los Haro en el Livro de linhagens del conde de Barcelos, "Anuario de estudios medievales" 43/2, pp. 833-869.

Pujante Martínez, Ana (1997), La torre vieja de Alguazas. Una fortaleza medieval de la vega del Segura, "Memorias de Arqueología" 6, pp. 474495.

Ruiz Asencio, José Manuel (1994), Colección Documental de la Catedral de León IX (1269-1300), León, Centro de Estudios e investigación San Isidoro.

Ruiz-Domènec, José Enrique (2009), La trama històrica d'un casament reial, en Princeses de terres llunyanes: Catalunya i Hongria a l'edat mitjana, Barcelona, Generalitat de Catalunya, pp. 201-215.

Ser Quijano, Gregorio del (ed.) (2000), Documentación medieval en archivos municipales abulenses, Ávila, Institución Gran Duque de Alba.

St. John, Lisa Benz (2012), Three Medieval Queens. Queenship and the Crown in Fourteenth-Century England, Nueva York, Palgrave Macmillan.

Stafford, Pauline (1997), Queen Emma and Queen Edith. Queenship and Women's Power in Eleventh-Century England, Oxford, Blackwell.

Torres Fontes, Juan (1960), Repartimiento de Murcia, Madrid, CSIC.

Torres Fontes, Juan (1963), La repoblación murciana en el siglo XIII, "Murgetana" 20, pp. 5-21.

Torres Fontes, Juan (1977), El señorío de Alguazas en la Edad Media, "Murgetana" 49, pp. 81-114.

Vajay, Szabols de (2009), Domina reginae milites. L'aclimatació dels hongareses del sèquit de Violant a la València conquerida, en Princeses de terres llunyanes: Catalunya i Hongria a l'edat mitjana, Barcelona, Generalitat de Catalunya, pp. 245-259.

Valdeón, Julio (2003), Alfonso X el Sabio. La forja de la España moderna, Madrid, Temas de Hoy.

Valls-Taberner, Ferran (1919), Relacions familiars i polítiques entre Jaume el Conqueridor i Anfos el Savi, "Bulletin Hispanique" 21, pp. 9-52.

Vargas-Zúñiga y Montero de Espinosa, Antonio; Cuartero y Huerta, Baltasar (eds.) (1949), Índice de la colección de don Luis de Salazar y Castro, t. 23, Madrid, Real Academia de la Historia.

Fecha de recepción del artículo: mayo 2015

Fecha de aceptación y versión final: enero 2016 